\title{
FOXD1 regulates cell division in clear cell renal cell carcinoma
}

Kyle H. Bond ${ }^{1,2}$, Jennifer L. Fetting ${ }^{3,4}$, Christine W. Lary ${ }^{3}$, Ivette F. Emery ${ }^{3}$ and Leif Oxburgh ${ }^{1 *}$ (D)

\begin{abstract}
Background: Forkhead transcription factors control cell growth in multiple cancer types. Foxd1 is essential for kidney development and mitochondrial metabolism, but its significance in renal cell carcinoma (ccRCC) has not been reported.

Methods: Transcriptome data from the TCGA database was used to correlate FOXD1 expression with patient survival. FOXD1 was knocked out in the 786-O cell line and known targets were analyzed. Reduced cell growth was observed and investigated in vitro using growth rate and Seahorse XF metabolic assays and in vivo using a xenograft model. Cell cycle characteristics were determined by flow cytometry and immunoblotting. Immunostaining for TUNEL and $\mathrm{YH} 2 \mathrm{AX}$ was used to measure DNA damage. Association of the FOXD1 pathway with cell cycle progression was investigated through correlation analysis using the TCGA database.

Results: FOXD1 expression level in cCRCC correlated inversely with patient survival. Knockout of FOXD1 in 786-O cells altered expression of FOXD1 targets, particularly genes involved in metabolism (MICU1) and cell cycle progression. Investigation of metabolic state revealed significant alterations in mitochondrial metabolism and glycolysis, but no net change in energy production. In vitro growth rate assays showed a significant reduction in growth of 786-OFOXD1null. In vivo, xenografted 786-OFOXD1null showed reduced capacity for tumor formation and reduced tumor size. Cell cycle analysis showed that 786-OFOXD1null had an extended G2/M phase. Investigation of mitosis revealed a deficiency in phosphorylation of histone H3 in 786-OFOXD1null, and increased DNA damage. Genes correlate with FOXD1 in the TCGA dataset associate with several aspects of mitosis, including histone H3 phosphorylation.

Conclusions: We show that FOXD1 regulates the cell cycle in cCRCC cells by control of histone H3 phosphorylation, and that FOXD1 expression governs tumor formation and tumor growth. Transcriptome analysis supports this role for FOXD1 in CCRCC patient tumors and provides an explanation for the inverse correlation between tumor expression of FOXD1 and patient survival. Our findings reveal an important role for FOXD1 in maintaining chromatin stability and promoting cell cycle progression and provide a new tool with which to study the biology of FOXD1 in cCRCC.
\end{abstract}

Keywords: Cell cycle, DNA damage, Forkhead, Kidney cancer

\footnotetext{
* Correspondence: leo9022@nyp.org

${ }^{1}$ The Rogosin Institute, 310 East 67th Street, New York, NY 10065, USA

Full list of author information is available at the end of the article
}

(c) The Author(s). 2021 Open Access This article is licensed under a Creative Commons Attribution 4.0 International License, which permits use, sharing, adaptation, distribution and reproduction in any medium or format, as long as you give appropriate credit to the original author(s) and the source, provide a link to the Creative Commons licence, and indicate if changes were made. The images or other third party material in this article are included in the article's Creative Commons licence, unless indicated otherwise in a credit line to the material. If material is not included in the article's Creative Commons licence and your intended use is not permitted by statutory regulation or exceeds the permitted use, you will need to obtain permission directly from the copyright holder. To view a copy of this licence, visit http://creativecommons.org/licenses/by/4.0/ The Creative Commons Public Domain Dedication waiver (http://creativecommons.org/publicdomain/zero/1.0/) applies to the data made available in this article, unless otherwise stated in a credit line to the data. 


\section{Background}

Forkhead transcription factors play diverse roles in cancer cells [1]. Members of the FOXA, C, M, O, and $\mathrm{P}$ subfamilies are involved in cancer initiation, progression and drug resistance. Expression of several forkhead family members has been described in clear cell renal cell carcinoma (ccRCC), a highly angiogenic tumor originating from nephron epithelium in the cortex of the kidney [2, 3].

The forkhead transcription factor FOXD1 plays an essential role in kidney development [4], and because developmental programs are frequently misregulated in cancer, we were interested to know what role it plays in cancer of the adult kidney, specifically ccRCC which is the most common form. Studies in other types of cancer suggest that it may be an important determinant of tumor biology. FOXD1 is highly expressed in Hodgkin's lymphoma and in breast cancer, where it suppresses p27 expression, thereby promoting cell proliferation [5]. In non-small cell lung cancer, FOXD1 expression correlates with poor survival and increases proliferation [6]. In glioma, FOXD1 expression correlates with tumor grade and influences proliferation and migration of cells [7]. FOXD1 expression is also downregulated in chemoresistant ovarian cancers [8].

In this study, we defined an inverse correlation between probability of survival in ccRCC patients and expression of FOXD1 in their tumors. A knockout was generated to investigate the biological function of FOXD1 in ccRCC cells. Expression of the known transcriptional target MICU1, a regulator of mitochondrial bioenergetics, was increased. While a shift in balance between mitochondrial respiration and glycolysis was seen, overall energy production in null cells was unaltered. Inactivation of FOXD1 caused a significant reduction in cellular proliferation both in vitro and in tumor xenograft assays, and studies of cells with synchronized cycling times revealed that the G2/M phase of the cell cycle was extended in mutant cells. Transcriptional pathway analysis in patient tumors supported this finding, and investigation of phosphorylation state of histone $\mathrm{H} 3$ revealed that it is almost completely abrogated in FOXD1 null cells. We propose that FOXD1 is required for histone $\mathrm{H} 3$ phosphorylation, which is an essential step in the transition through G2/M.

\section{Methods}

\section{Experimental model and subject details Cell lines}

786-O (ATCC CRL-1932 $^{\mathrm{Tm}}$ ) cells and 786-O FOXD1null were maintained in RPMI 1640 with $1 \mathrm{x}$ GlutaMax, 25mM HEPES, 10\% FBS, and 1x penicillin-streptomycin in $37{ }^{\circ} \mathrm{C}$ cell culture incubators at $5 \% \mathrm{CO}_{2}$. Cells were passaged for expansion using TrypLE express. For immunostaining, cells were grown on gelatin-coated sterile coverslips. Mycoplasma testing was performed prior to all experimental testing.

\section{In vivo animal studies}

Animal care was in accordance with the National Research Council Guide for the Care and Use of Laboratory Animals, and all experiments were approved by the Institutional Animal Care and Use Committee of New York Blood Center, where the Rogosin Institute laboratory is located. All animal experiments followed the housing protocols of the New York Blood Center: Complete health surveillance testing is performed for each murine room quarterly. Interim testing is performed as necessary. Serology is performed by Charles River Laboratories. Parasitology is performed in-house. The mice are housed in ventilated microisolator cages with 1 cup of $1 / 8$ in. Bed-o'cobs. Mice are on 5 P76 rodent feed and acidified water. Full PPE including head and shoe covers, isolation gown, mask and gloves, are required before room entry. All procedures are done inside a hood. Once animals leave the room, they do not return. Cages and water bottles are changed weekly and other cage materials are changed every 2 weeks. 6 week old female $\mathrm{NCr}$ nude mice (CrTac:NCr-Foxn1nu) were purchased from Taconic and housed at the New York Blood Center animal facility. Animals were housed in groups of 3-4 per cage. To establish xenografts, 786-O cells and 786- $\mathrm{O}^{\mathrm{FOXD1} \text { null }}$ were expanded, resuspended at 10 million cells per $200 \mu \mathrm{l}$ PBS and injected subcutaneously in the right flanks of 6-week old $\mathrm{NCr}$ mice, 6 animals per cell type. $48 \mathrm{~h}$ post-injection, tumor volume was measured using electronic calipers $\left(\mathrm{V}=\mathrm{LxW}^{2}\right)$. Tumor establishment was determined 7 days from first measurement, as determined from pilot studies (Fig. S3). Tumor growth was monitored every 2-3 days for 60 days. At the end-point, animals were euthanized with isoflurane followed by cervical dislocation.

\section{Methods detail TCGA data analysis}

Level 3 RNA sequencing data from the Illumina HiSeq platform was downloaded from the TCGA data portal (www.cancergenome.nih.gov) for 20,532 genes and 528 unique samples. We used the RPKM (reads per kilobase mapped) as gene expression values and linked this data to the clinical patient data using the patient barcode. Kaplan-Meier analyses were performed by stratifying gene expression data for each gene at the median and tested using the log-rank statistic. The survdiff and survtest $R$ functions were using for Kaplan-Meier analyses, and the coxph function was used for fitting a Cox Proportional Hazards model to each gene to obtain the hazard ratio. 


\section{Patient samples}

One hundred and forty two de-identified formalin-fixed, paraffin-embedded ccRCC samples from resected tumors were obtained from the Maine Medical Center BioBank, which obtains surgical samples with the written informed consent of patients. This study was approved by the Maine Medical Center Institutional Review Board (IRB \#4202X and IRB \#4392).

\section{Immunohistochemistry}

Section immunostaining was conducted as previously described [9]. Primary antibody FOXD1 (1:100, LSBio LS-B6453) and biotinylated rabbit anti-goat (1:500, Vectorlabs BA-5000) were used for immunohistochemistry using Vectastain ABC Elite kit (Vectorlabs PK-7100), and the color reaction performed using DAB. FOXD1 immunofluorescence in embryonic sections was amplified using the TSA amplification kit per manufacturer's instructions (Perkin Elmer NEL756001KT).

\section{FIJ analysis and quantification of expression}

To quantify molecular marker expression, immunostained tumor sections were imaged at five separate regions, and the percentage of stained cells in each image was calculated using FIJI and used to calculate FOXD1 staining confidence ratio. To assign FOXD1+ scores to individual tumors, the mean percentage of FOXD1+ cells from all five images was calculated.

\section{Generation of the 786-O $0^{\text {FOXD1null }}$ line}

786-O cells (ATCC: CL-188; 70,003,535) were the parental cells used to generate a pool of FOXD1-null cells. CRISPR/Cas9-mediated knockout cells were generated by the Synthego Corporation (Cambridge, MA, USA). In brief, guide RNAs were designed to create premature stop codons through frameshift mutations in the coding region via insertions and/or deletions (Indels) directly upstream of the start codon of FOXD1. The following sgRNA sequence was used: 5' AUCGGACAUCUCAG UGCUCA-3' [GGG]-PAM. To generate these cells, ribonucleoproteins (RNPs) containing the Cas9 protein and synthetic sgRNA were electroporated into the cells. Editing efficiency was assessed upon recovery, $48 \mathrm{~h}$ postelectroporation. Genomic DNA was extracted, PCRamplified, sequenced using Sanger sequencing, and analyzed for editing efficiency using Synthego Inference of CRISPR Edits (ICE) software (ice.synthego.com). Limiting dilution was performed to generate 84 clonal populations and screened for indels using ICE software as described above. Top scoring lines were analyzed for FOXD1 protein expression using immunocytochemistry described below.
qPCR analysis of predicted FOXD1 targets

RNA was extracted from 786-O and 786-O ${ }^{\text {FOXD1null }}$ cells at $70 \%$ confluency using Qiagen RNeasy Minikit (Qiagen Cat\#74134) with DNase step included. cDNA was generated using BioRad iScript Synthesis kit (BioRad Cat\#1708891). A screen of 31 reference genes was performed using BioRad SsoAdvanced Universal SYBR Green Supermix using the manufacturer's protocol, and selection of appropriate reference genes was performed using BioRad CFX Maestro software Reference Gene Selector Tool. RPLP $P O, H B B$, and $B 2 M$ were chosen for this application. qPCR primers of predicted FOXD1 target genes were assayed and fold changes were calculated using BioRad CFX Maestro software using parental 786-O as reference. All assays were performed on CFX384 or CFX96 Touch Real-Time PCR Detection Systems, in triplicates.

\section{Immunocytochemistry analysis}

Immunostaining for FOXD1 in cells is described in brief; cells were fixed in 4\% PFA for $12 \mathrm{~min}$ at room temperature, permeabilized with $0.2 \%$ Triton X-100 for $10 \mathrm{~min}$ at room temperature and blocked with $10 \%$ chicken serum in PBS for $1 \mathrm{~h}$ at room temperature. Binding of FOXD1 primary antibody (1:100, LSBio Cat\#LS-B6453), biotinylated chicken anti-goat (1:250, ImmunoReagents Cat\#CkxGt-003-EBio), and Cy5conjugated streptavidin (1:250, Jackson Immunoresearch Cat\#016-170-084) were performed sequentially at room temperature, $1 \mathrm{~h}$ each step and counterstained with DAPI. Coverslips were mounted using ProLong Diamond (Invitrogen Cat\#P36961) mounting medium. The staining protocol was modified for phosphoproteins $\gamma \mathrm{H} 2 \mathrm{AX}$ (1:400, EMD Millipore Cat\#05-636) and pH3 (1:100, EMD Millipore Cat\#06-579) as follows; cells were fixed in ice cold 100\% methanol and blocked overnight with $10 \%$ goat serum and $0.1 \%$ BSA in TBS. Primary antibody incubation was performed overnight, followed by secondary antibody incubation in goat antimouse IgG1 Alexa Fluor 568 (Life Technologies Cat\#A21124) and goat anti-rabbit Alexa Fluor 647 (Life Technologies Cat\#A21245). Coverslips were counterstained with DAPI, phalloidin Oregon-green (Invitrogen Cat\#07466), or EdU (Invitrogen Cat\#C10337) as pertaining to experiment. Staining for mitochondria using TOMM20 (1:100, abcam Cat\# ab186735) was performed using standard immunocytochemistry techniques. Coverslips were mounted in EverBrite Mounting Media (Biotium Cat\#23001). All staining was repeated to confirm staining patterns.

\section{In vitro growth rate analysis}

Five thousand cells of $786-\mathrm{O}$ parent or $786-\mathrm{O}^{\text {FOXD1null }}$ were plated into each well of a 6-well plate. Every $24 \mathrm{~h}$ for 4 days, cells were trypsinized and counted in 
triplicates. After 4 days, cells were collected and counted every $48 \mathrm{~h}$. This experiment was repeated 3 times.

\section{DNA damage analysis (TUNEL)}

$786-\mathrm{O}$ or $786-\mathrm{O}^{\text {FOXD1null }}$ cells were plated in 8-well chamber slides and cultured for $24 \mathrm{~h}$. Cells were then fixed in $4 \%$ paraformaldehyde, permeabilized with 2:1 ethanol:acetic acid, and DNA damage was detected using the ApopTag ${ }^{\circ}$ Red In Situ Apoptosis Detection Kit (Millipore Cat\#S7165). In brief, damaged DNA was tagged with digoxigenin-dNTP, then detected using a fluorescently conjugated anti-digoxigenin antibody. Cells were counterstained with DAPI. Extent of DNA damage was analyzed by counting the number of TUNEL positive foci per nucleus in approximately 300 cells in each group.

\section{Metabolic analyses}

Two thousand cells of 786-O and 786- ${ }^{\text {FOXD1null }}$ were plated into Seahorse XF96 Cell Culture Microplates and assayed using XF Glycolytic Rate Assay $(N=2)$ (Agilent Cat\#103592-100), XF Cell Mito Stress Test $(N=3)$ (Agilent Cat\#103015-100), or XF ATP Real-Time rate assay $(N=2)$ (Agilent Cat\#103020-100) following manufacturer procedures. Six technical replicates were analyzed for each biological replicate.

\section{EdU pulse-chase analysis}

786-O parent and 786-O ${ }^{\text {FOXD1null }}$ were treated ("pulse") with $5 \mu \mathrm{M}$ EdU for 6,8 , or $10 \mathrm{~h}$. After treatment, cells were washed and media was replaced with standard cell culture media. Cells were cultured ("chased") for an additional $0,2,4$, or $6 \mathrm{~h}$. At each time point, cells were fixed in $100 \%$ ice cold methanol and stored in TBS at $4{ }^{\circ} \mathrm{C}$ until all time points were collected. Following all collections, cells were stained using the ICC protocol above, and counterstained with DAPI. EdU was detected following the manufacturer's protocol. Cells were imaged using a Leica Thunder Imager. Cells were analyzed for co-expression of EdU, $\gamma \mathrm{H} 2 \mathrm{AX}$, and $\mathrm{pH} 3$ using the Leica LasX multi-channel analysis package.

\section{Cell cycle analysis}

786-O parent and 786-O ${ }^{\text {FOXD1null }}$ were synchronized using double thymidine block. In brief, cells were treated for $16 \mathrm{~h}$ with thymidine, washed, and cultured for $9 \mathrm{~h}$. A second round of thymidine was added for an additional $16 \mathrm{~h}$ to synchronize cells into G1. Cells were washed and fresh media was added. Cells were collected at various time points and either fixed in $100 \%$ ice cold methanol or protein extracted using Laemmli Buffer. Following fixation, cells were stained overnight with DAPI at $4{ }^{\circ} \mathrm{C}$ before flow cytometry. Flow cytometry was conducted at New York Blood Center Flow Cytometry Core Facility.
Cell cycle distribution was performed on Flowjo software. Entry into mitosis was determined by Western blot analysis staining for H3 (CST Cat\#9706 L), pH3(Ser10) (CST Cat\#9715), CDC2 (CST Cat\# 28439S), pCDC2(Tyr15) (CST Cat\#9111S), pCDC2 (Thr161) (CST Cat\#9114S), and CyclinB1 (CST Cat\#12231). Molecular weight and densitometry analysis were performed using BioRad Imagelab software and normalized to total protein loaded.

\section{In silico FOXD1 molecular signaling pathway prediction analysis}

Gene correlation values were ranked for correlation strength and analyzed using Gene Set Enrichment Analysis (GSEA), mapping pathway interactions using the Reactome database and further analyzed using Gene Ontology (GO) analysis [10]. Pathways and interactors were mapped using Cytoscape [11]. Genes involved in pathways grouped under "Cell Cycle" were summarized and marked for further investigation.

\section{Quantification and statistical analysis}

For in vivo experiments, 3-4 animals were used per group. Due to the low tumor retention rate after 2 weeks of $786-\mathrm{O}^{\text {FOXD1null }}(12.5 \%)$, statistical comparisons between end-point tumor size at 60 days were not possible, and instead comparisons at 15 and 30 days were performed, using Student's two tailed t-test. All in vitro experiments utilized the Student's t-test for comparisons between 786-O and 786- $\mathrm{O}^{\text {FOXD1null }}$. Correlation analyses were conducted using either the Pearson or Spearman rank correlation as implemented with the $\mathrm{R}$ function cor.test, and chi-squared tests were conducted to test the association between dichotomized variables.

\section{Results \\ FOXD1 expression in ccRCC correlates with poor patient survival}

To understand if there could be a role for FOXD1 in ccRCC, we correlated tumor expression with patient outcomes using data from The Cancer Genome Atlas (TCGA). Five hundred and twenty-eight ccRCC cases were grouped into high or low FOXD1 expression relative to the median. Patients with FOXD1-low tumors showed significantly higher probability of survival at all time-points analyzed (Fig. 1a), supporting a role for tumor expression of FOXD1 in disease progression. Comparison of FOXD1 expression in tumors of different grades showed higher FOXD1 levels in higher grades (G1 vs. G3 $p=1.2 \times$ $10^{-2}$; G1 vs. G4 $p=5.0 \times 10^{-4}$; G2 vs. G3 $p=3.8 \times$ $10^{-2}$; G2 vs. G4 $p=1.4 \times 10^{-3}$ ) (Fig. S1A). Comparison of FOXD1 expression at different tumor stages revealed a significant difference only between stage 1 

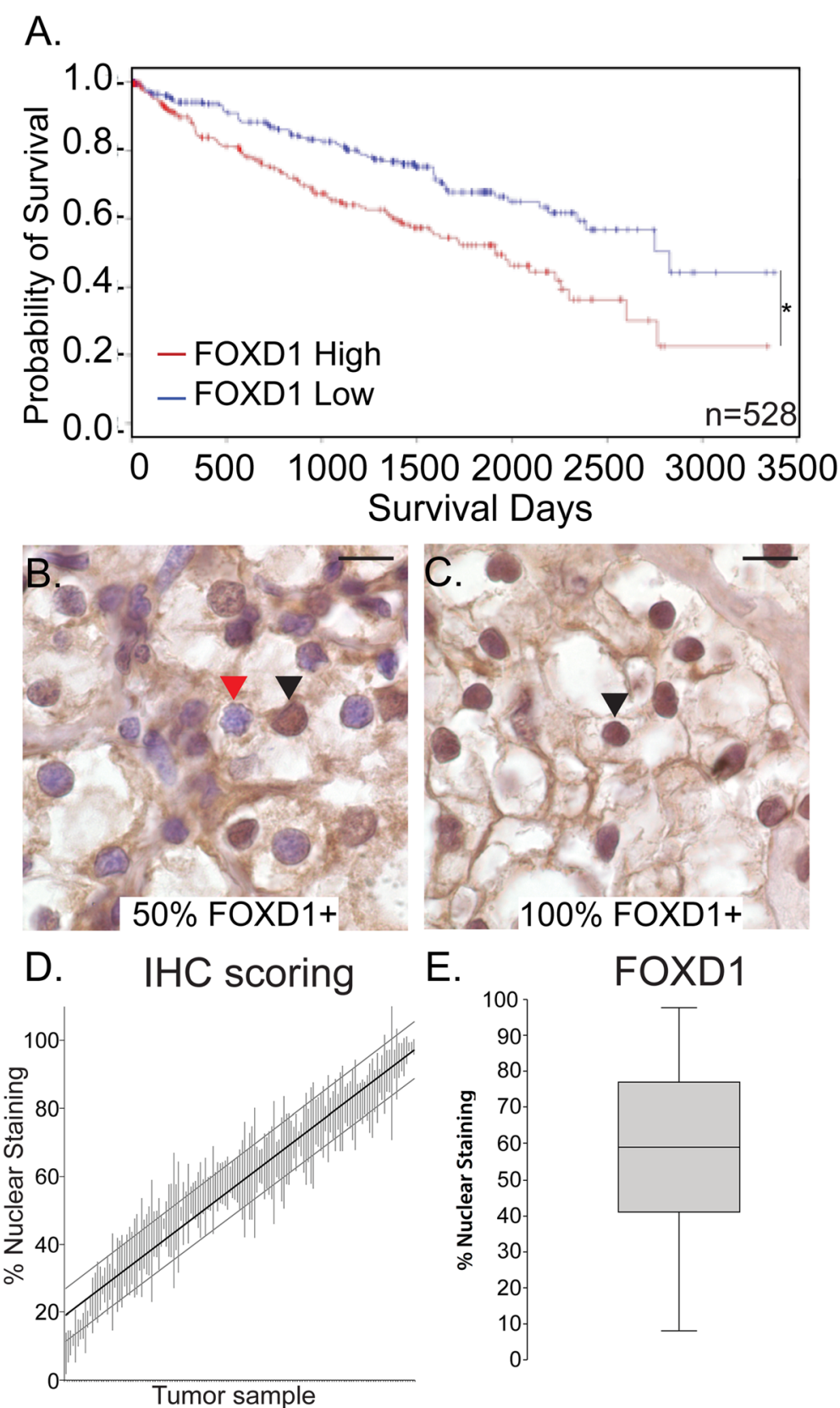

E.

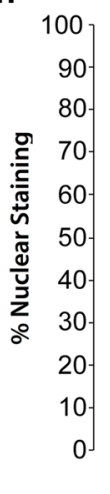

FOXD1

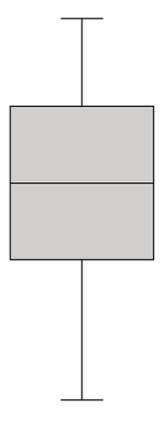

Fig. 1 FOXD1 expression in ccRCC. a Kaplan-Meier survival analysis for ccRCC patients with high versus low tumor expression of FOXD1 based on transcriptome data from The Cancer Genome Atlas (TCGA). High and low expression were plotted relative to median expression of FOXD1. ${ }^{*} p=$ 6.85E-05. b-e FOXD1 expression in ccRCC tumors. Representative examples of tumors with mosaic nuclear staining $\mathbf{b}$ and ubiquitous nuclear staining c. Black arrows indicate positive and red arrow indicates negative nuclei. d Scoring of percentage nuclear staining in 142 resected ccRCC tumors. For each tumor, five high power fields were scored for percentage of positive nuclei. e The median percentage of FOXD1-positive nuclei in tumors is $58.15 \%(95 \% \mathrm{Cl} 50.6$ to 65.7$)$

and stage 4 (S1 vs. S4 $p=1.9 \times 10^{-2}$ ) (Fig. S1B). We further investigated if increased FOXD1 expression could have poor outcomes related to any particular stage and found that high FOXD1 expression significantly correlated with worse outcomes for patients at stages 2 and 3 (stage $2 p=4.5 \times 10^{-2}$; stage $3 p=$ $3.3 \times 10^{-3}$ ) (Fig. S1C-F).
To define the expression pattern of the FOXD1 transcription factor in ccRCC, we immunostained 142 patient tumors with a histopathological diagnosis of ccRCC (Table S1). Considering the high degree of relatedness between forkhead proteins, cross-reactivity of antisera presents a problem. To identify a FOXD1specific antibody for these studies, we used Foxd1 null 
mice to screen for specificity. Foxd1 is strongly and specifically expressed in cortical interstitial cells of the developing kidney [4]. Comparison of immunohistochemical staining using several commercial FOXD1 antibodies revealed that the LS Bio FOXD1 antibody (LSB6453) showed specificity for nuclear FOXD1 in cortical interstitial cells of the developing kidney and did not stain Foxd1 null tissue (Fig. S2A,B). In immunohistochemistry, diffuse staining is seen in epithelial tubules of adult human kidney tissue (Fig. S2C), and immunohistochemical analysis of Foxd1 null mouse tissue reveals a similar pattern (Fig. S2D), indicating that this is antibody trapping. For this reason, we limited our analysis to nuclear staining. Nuclear FOXD1 was observed in all tumors (Fig. 1b ,c), with extensive inter-tumor variability in proportion of positive nuclei (Fig. 1d). Taking into account the variability of scores between and within samples, we generated a 95\% confidence interval for proportion of FOXD1-positive nuclei in tumors as 58.15 $+/-7.55 \%$ (Fig. 1e). We note a potential bias in that a fraction of patients $(8 / 142)$ received neoadjuvant treatment prior to sample collection. As expected, approximately $50 \%$ of Stage IV tumors were from treated patients, and any effect of treatment on FOXD1 expression would primarily be seen in this group. However, the proportion of tumors from treated patients overall is approximately $5 \%$ and would only constitute a minor effect on the aggregated data if FOXD1 expression is affected by neoadjuvant treatment.

\section{Effect of FOXD1 knockout on expression of known transcriptional targets}

To understand the function of FOXD1, we generated a loss of function renal cell carcinoma cell line using CRIS PR/Cas9. The 786-O cell line, which has a mutation in the $V H L$ gene, is diploid for chromosome 5 on which FOXD1 is located [12] and is therefore a good candidate cell line in which to generate a loss of function. A guide sequence was identified that would cleave the gene 4 codons downstream of the ATG and enable selection of edited clones with insertions or deletions causing truncating mutations (Fig. 2a). Inference of CRISPR Edits (ICE), a regression algorithm for predicting editing outcomes from Sanger sequencing data, was used to predict knockout of FOXD1 in clones of edited cells (Fig. 2b). Clone 2, with a single thymine insertion at the same position in both copies of FOXD1, was predicted to encode a protein that is truncated 4 amino acids downstream of the methionine (Fig. 2c). Sequencing of the top potential off-target genes revealed no unwanted modifications (Table S2). Immunostaining showed an absence of FOXD1 in the nucleus and cell body of Clone 2 (Fig. 2d). We conclude that Clone 2 carries a null mutation in FOXD1 originating from a homozygous single nucleotide insertion, and we refer to it hereafter as $786-\mathrm{O}^{\mathrm{FOXD} 1 \text { null }}$.

To understand transcriptional effects of inactivating FOXD1, we compiled a list of candidate targets from previous reports $[9,13-15]$. To ensure accurate measurement of expression by RT-QPCR, we selected reference genes with stable expression between $786-\mathrm{O}$ and 786-O $\mathrm{O}^{\mathrm{FOXD1} 1 \text { ull }}$. Commonly used reference genes such as GAPDH, HPRT, TUBB, and TBP showed very poor stability between these cell lines (Fig. S3A). We selected RPLPPO, B2M, and HBB (Fig. S2B-D), and used the geometric mean of these three assays as the reference value. Target genes associated with the cell cycle were misregulated, with the exception of PRC1, suggesting a cell cycle perturbation (Fig. 2e). DCN, PGF, PUM1, and MICU1 were also misregulated in $786-\mathrm{O}^{\text {FOXD1null }}$

\section{FOXD1 influences cellular energetics, but does not affect overall ATP production}

Considering that ccRCC is a disease of cellular metabolism, misregulation of MICU1 is particularly interesting because it affects calcium signaling between cytoplasm and mitochondria [14]. In agreement with previous studies, our data shows that FOXD1 represses MICU1 transcription [14]. Immunoblot revealed a significant increase in MICU1 protein in the 786-O ${ }^{\mathrm{FOXD} 1 \text { null }} \mathrm{com}$ pared to the parent 786-O (Fig. 3a). To understand if this reflects an increased abundance of mitochondria in the 786- $\mathrm{O}^{\text {FOXD1null, }}$, we immunostained both lines for the mitochondrial marker TOMM20, and found increased signal intensity in $786-\mathrm{O}^{\mathrm{FOXD} 1 \text { null }}$, suggesting increased mitochondrial abundance (Fig. 3b, c). To test if this altered utilization of oxidative metabolism, we compared 786-O versus $786-\mathrm{O}^{\text {FOXD1null }}$ using Seahorse XF. Surprisingly, we found a significant reduction in basal mitochondrial respiration in 786$\mathrm{O}^{\text {FOXD1null }}$ (Fig. 3d), and an increase in basal glycolysis (Fig. 3e). However, total ATP production between the lines was equivalent (Fig. 3f), indicating that energy derived from increased glycolysis compensates for the decrease in mitochondrial respiration. Thus, despite elevated MICU1 expression and evidence of increased mitochondrial abundance, mitochondrial respiration is depressed in the $786-\mathrm{O}^{\mathrm{FOXD} 1 \text { null. }}$. The 786-O cell line has a $V H L$ inactivating mutation and is constitutively hypoxic with elevated baseline expression of HIF2. Persistent expression of HIF transcription factors represses respiratory chain subunits [16], and we therefore analyzed expression of genes in the mitochondrial respiration pathway (Fig. 3g). Modest changes were found for electron transport chain components, with $U Q R C 2$ and COXIV showing elevated expression in $786-\mathrm{O}^{\text {FOXD1null. The ATP transporters }}$ ANT1 and ANT2 both showed significant changes, 

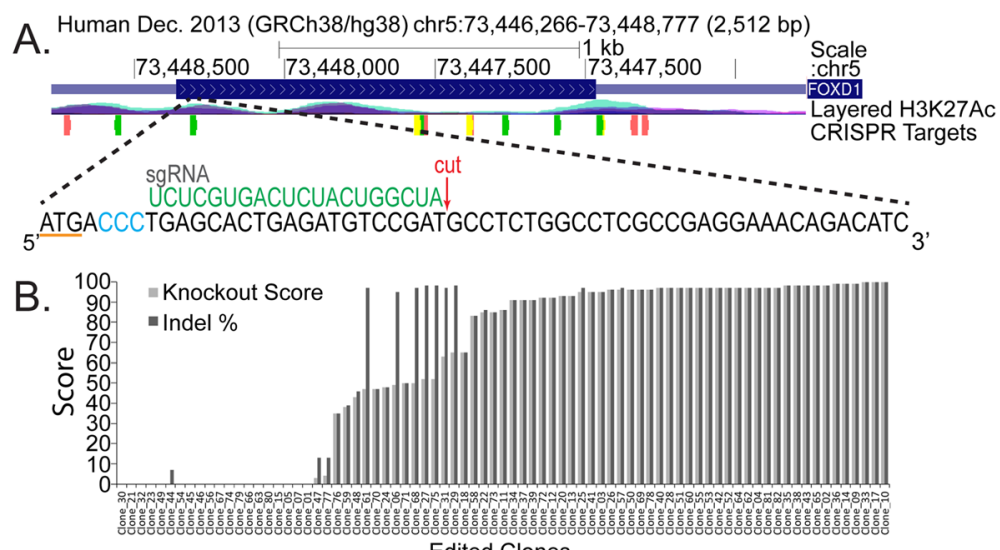

C.
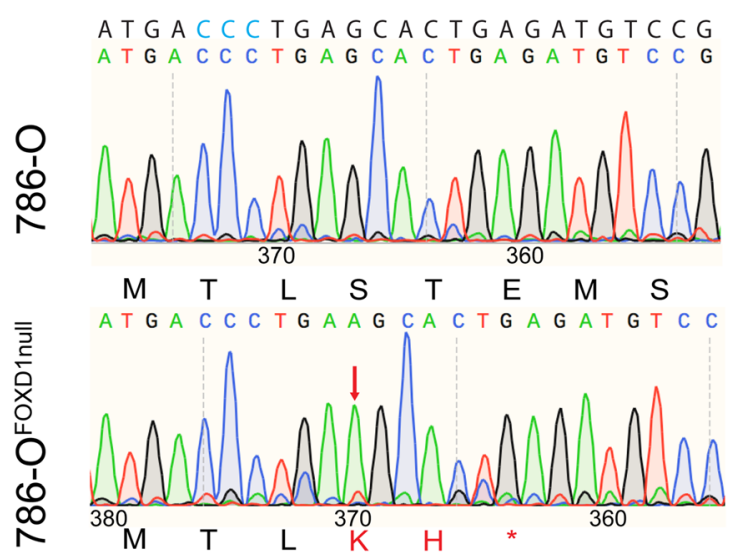

D. 786-0

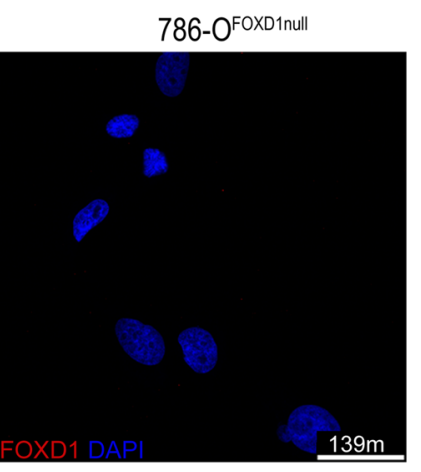

E.

786-O $\square 786-0^{\text {FoxD1null }}$

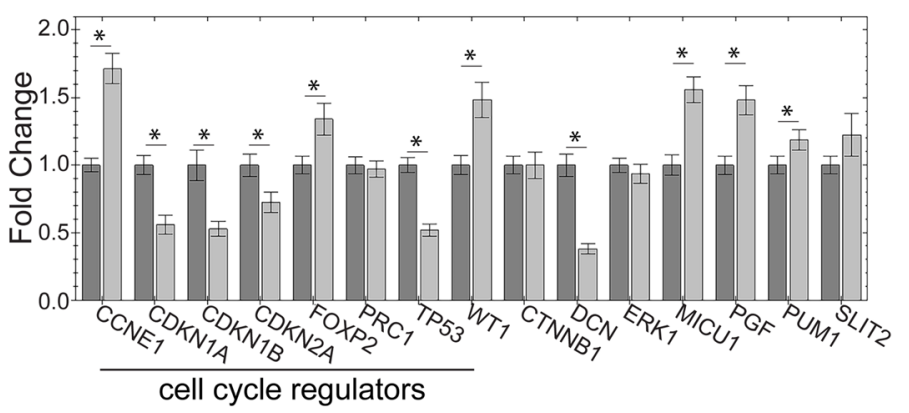

Fig. 2 (See legend on next page.) 
(See figure on previous page.)

Fig. 2 FOXD1 knockout affects expression of cell cycle regulators and alters cellular energetics. a CRISPR/Cas9 knockout targeting strategy for FOXD1. The FOXD1 locus on chromosome 5 shows the single FOXD1 exon with the CDS in dark blue and UTRs in light blue. The placement of the guide RNA (green) relative to the ATG (underlined) is shown below. $\mathbf{b}$ Knockout prediction score and percentage of alleles with insertions or deletions (indels) for 82 clones isolated from the CRISPR-edited pool. Chromosome 5 is diploid in 786-O and clones with $50 \%$ indel frequency are predicted to be heterozygous, while those with $100 \%$ indel frequency are predicted to be homozygous. c Sequencing trace of 786-O versus $786-$

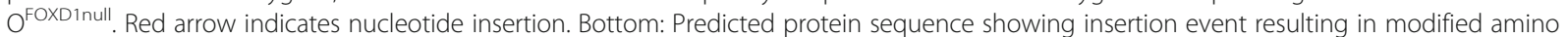
acid sequence (red text) and premature stop $\left(^{*}\right)$. d FOXD1 (red) immunofluorescence staining in 786-O versus 786-O ${ }^{\text {FOXDInull }}$, counterstained with DAPI (blue). e Expression of predicted FOXD1 target genes in edited versus parent cells. ${ }^{*} p<0.05$

but in opposite directions making the net effect unclear. Expression of genes encoding pyruvate dehydrogenase kinase 1 (PDK1) and pyruvate dehydrogenase phosphatase catalytic subunit 1 (PDP1) was significantly elevated. PDK1 and PDP1 act in opposition on the enzyme pyruvate dehydrogenase, which is essential for energy production from the TCA cycle. Their simultaneous upregulation in the $786-\mathrm{O}^{\mathrm{FOXD1null}}$ suggests that elevated PDK1 may inhibit the TCA cycle, reducing mitochondrial respiration [17], with concomitant upregulation of the PDP1 phosphatase as a feedback response. This would be predicted to result in aerobic glycolysis being favored over mitochondrial metabolism in the $786-\mathrm{O}^{\mathrm{FOXD} 1 \text { null }}$ cell. In summary, although mitochondria may be more abundant in 786-O $\mathrm{O}^{\mathrm{FOXD} 1 n u l l}$, our data supports reduced mitochondrial energy production, and our gene expression analysis suggests inhibition of the TCA cycle.

\section{FOXD1 is essential for tumor growth in vivo}

Although total ATP production is unaffected by inactivation of FOXD1, proliferation is attenuated in 786$\mathrm{O}^{\text {FOXD1null }}$ (Fig. 4a), suggesting that effects on the cell cycle (Fig. 2e) may be primary rather than a consequence of energy deficit. To understand if the effect of FOXD1 on cellular proliferation is reflected in a tumor model, we xenografted cohorts of 6 nude mice with either $786-\mathrm{O}$ or $786-\mathrm{O}^{\text {FOXD1null }}$ (Fig. 4b) as previously






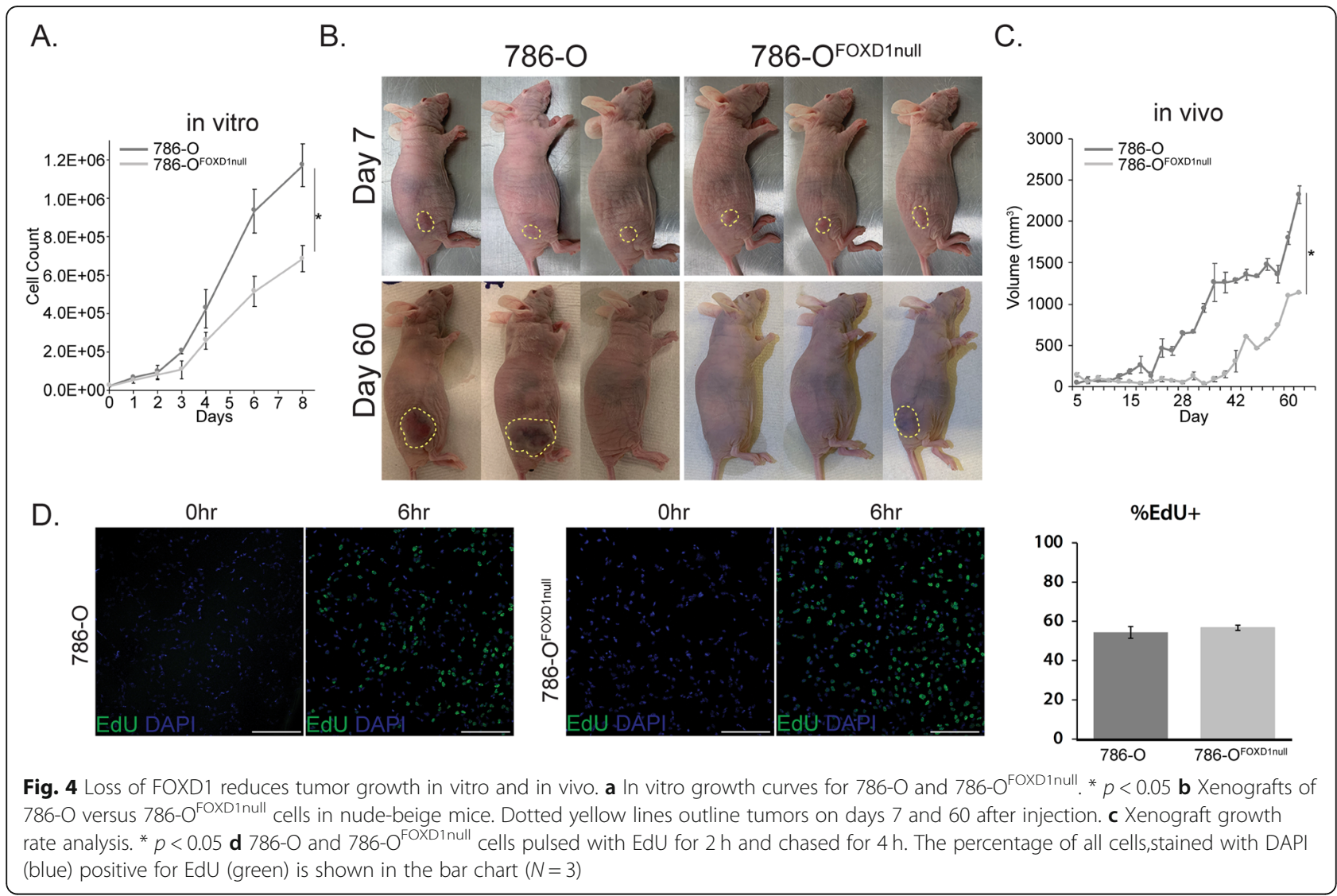

described [18, 19]. After tumor establishment, $70 \%$ of 786- $\mathrm{O}^{\text {FOXD1null }}$ tumors regressed, compared to only $30 \%$ for 786-O (Fig. S4A,B). 786-O ${ }^{\text {FOXD1null }}$ tumors that were established showed significantly reduced growth rate compared to 786-O (Fig. 4c). FOXD1 promotes expression of CDKN1A/p21 [20], and our expression analysis of $786-\mathrm{O}^{\text {FOXD1null }}$ showed reduced $C D K N 1 A / p 21$ expression (Fig. 2e). CDKN1A/p21 delays the G1 to $\mathrm{S}$ transition, and reducing its expression is predicted to accelerate cycling time, which is contradictory to our observations in vitro and in vivo. To investigate if FOXD1 inactivation influences the G1-S transition, we performed an EdU pulse-chase experiment to analyze the percentage of cells able to enter $\mathrm{S}$ phase. A $2 \mathrm{~h}$ EdU pulse followed by a $4 \mathrm{~h}$ chase did not show any difference in $S$ phase entry between 786-O and 786$\mathrm{O}^{\text {FOXD1null }}$ (Fig. 4d), and it is unlikely that the reduced proliferation in FOXD1 null cells is due to delayed G1-S transition.

\section{Loss of FOXD1 causes cell cycle delay at G2/M and inability to phosphorylate histone $\mathrm{H3}$}

To determine if the reduced proliferation caused by loss of FOXD1 may be due to stalling at the G2/M checkpoint, we synchronized cells with a double thymidine block and timed phases of the cell cycle by analyzing
DAPI incorporation (Fig. 5a). Corroborating the EdU analysis, both lines proceed at the same rate from G1 to $\mathrm{S}$ phase and by $8 \mathrm{~h}$ both have entered G2/M. While 786$\mathrm{O}$ cells have largely transitioned out of $\mathrm{M}$ by $10 \mathrm{~h}$, the transition of $786-\mathrm{O}^{\mathrm{FOXD} 1 n u l l}$ out of $\mathrm{M}$ is delayed by $2-4$ h. G2/M delay provides an explanation for the reduced growth of $786-\mathrm{O}^{\mathrm{FOXD1null}}$ in tumor xenografts and in vitro.

To further understand when cells pass the G2/M checkpoint, we investigated a panel of markers selected as follows. CDC2 and CyclinB1: The activated CDC2-CyclinB1 complex is necessary for progression through the G2/M checkpoint into mitosis [21]. CyclinB1 steadily rises through the early stages of the cell cycle until peaking at late G2, after which its level rapidly declines. $\mathrm{CDC} 2$, when phosphorylated on T161, activates the CDC2-CyclinB1 complex and initiates progression through the $\mathrm{G} 2 / \mathrm{M}$ checkpoint. However, phosphorylation at Y15 inactivates the complex and prevents progression through the checkpoint. In order for cells to proceed into mitosis, CDC2 would need phosphorylation at T161 and dephosphorylation at Y15. In 786-O cells, phosphorylation of CDC2 occurs at both T161 and Y15 until $10 \mathrm{~h}$, at which time phosphorylation of Y15 significantly decreases while T161 levels are still 


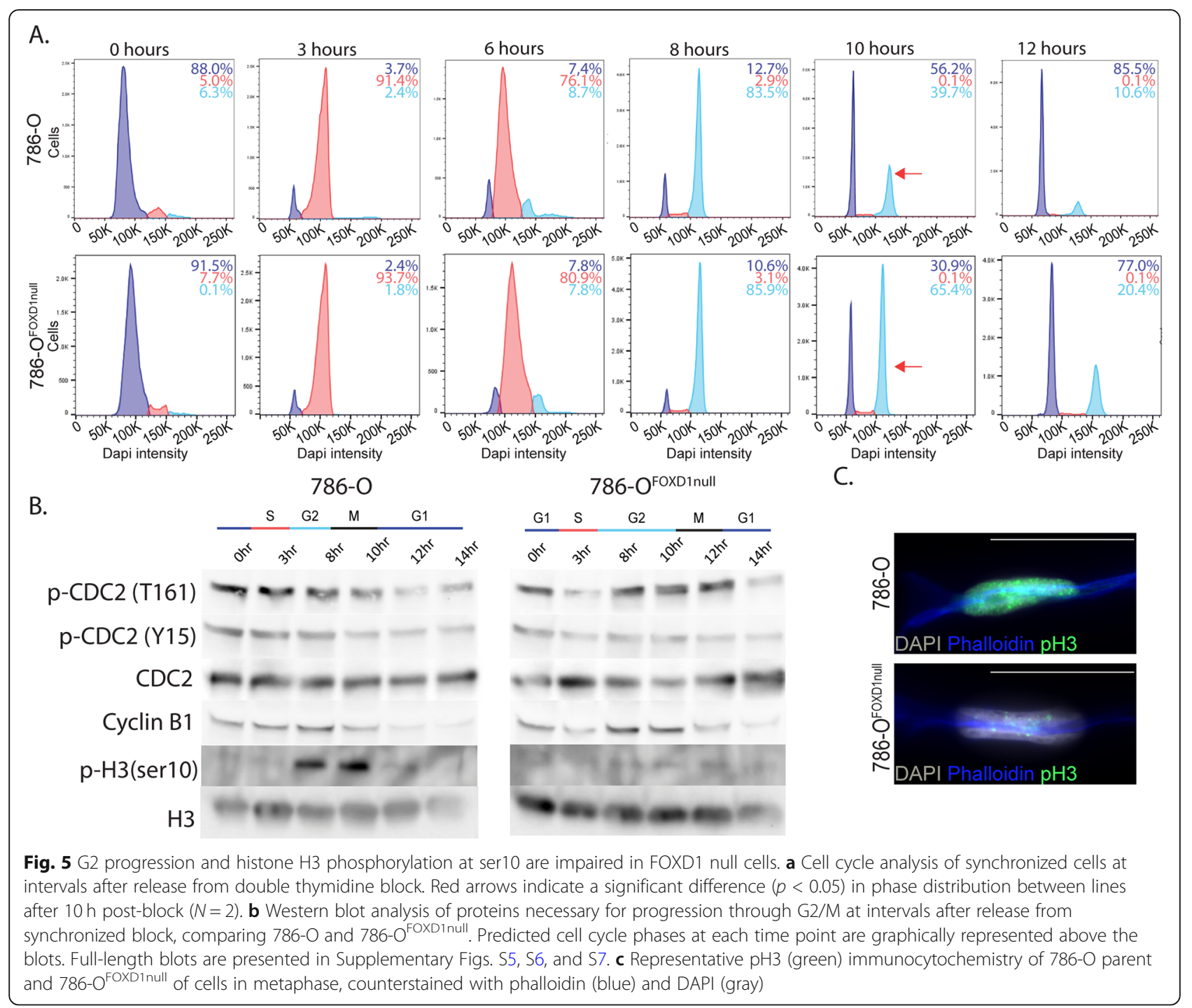

elevated. By $12 \mathrm{~h}$, phosphorylation at T161 significantly drops, indicating completion of mitosis. Additionally, CyclinB1 levels steadily increase until $8 \mathrm{~h}$ before rapidly dropping at $10 \mathrm{~h}$. This supports our previous prediction that cells enter $\mathrm{G} 2 / \mathrm{M}$ by $8 \mathrm{~h}$ post-synchronization, and complete mitosis by $12 \mathrm{~h}$ post-synchronization. In comparison, the 786$\mathrm{O}^{\text {FOXD1null }}$ cells maintain elevated p-CDC2(T161) levels through the same time course, only reducing levels at $14 \mathrm{~h}$. p-CDC2(Y15) levels in parallel showed constitutively high levels until $12 \mathrm{~h}$ postsynchronization. CyclinB1 peaks at $8 \mathrm{~h}$, like the parental line, but this level is maintained until $12 \mathrm{~h}$ post-synchronization. Serine 10 phosphorylation of histone $\mathrm{H} 3$ at promoter regions of select genes such as FOS and JUN [22] regulates abundance of the AP1 transcription factor that is required for expression of mitotic regulators including Aurora kinase B
[23]. Because of the abundance of this phosphorylation, it is commonly used as a marker of mitosis. We thus chose to look additionally at $\mathrm{pH} 3$ and found that 786-O ${ }^{\text {FOXD1null }}$ showed significantly reduced levels of $\mathrm{pH} 3$ compared to 786-O at the G2/ M-G1 interface (Fig. 5b, Fig. S5). Despite abundant expression of histone $\mathrm{H} 3$ in $786-\mathrm{O}^{\text {FOXD1null, phos- }}$ phorylation is very modest compared with 786-O.

Cells were immunostained to understand if the phosphorylation of $\mathrm{H} 3$ is reduced in all cells, or if there are fewer cells with $\mathrm{H} 3$ phosphorylation in 786-O $\mathrm{O}^{\text {FOXD1null }}$ compared with $786-\mathrm{O}$. All nuclei in $786-\mathrm{O}^{\text {FOXD1null }}$ showed depressed phosphorylation of H3. Phosphorylation of $\mathrm{H} 3$ peaks at metaphase, a stage that is defined histologically by colocalization of actin fibers with chromosomes. Comparing nuclei of 786-O with 786$\mathrm{O}^{\text {FOXD1null }}$ at this stage revealed little $\mathrm{pH} 3$ in the 786$\mathrm{O}^{\text {FOXD1null }}$ (Fig. 5c, Table S4). These findings support a 
requirement for FOXD1 in pan-chromosome phosphorylation of $\mathrm{H} 3$ serine 10. Overall, loss of FOXD1 results in prolonged time spent at the G2/M checkpoint and an inability to phosphorylate histone $\mathrm{H} 3$.

\section{FOXD1 expression is necessary for genomic integrity through mitosis}

A second essential function of histone $\mathrm{H} 3$ phosphorylation is the condensation of chromosomes, which depends on serine 10 phosphorylation of $\mathrm{H} 3$ throughout each chromosome [24]. Improper chromosome condensation promotes DNA damage [25], and we therefore compared strand breaks in 786-O with $786-\mathrm{O}^{\mathrm{FOXD} 1 \text { null }}$ by staining for TUNEL and found that 786- $\mathrm{O}^{\text {FOXD1null }}$ cells show a significantly increased numbers of TUNELpositive foci per nucleus than 786-O (Fig. 6a). Each TUNEL puncta represents DNA strand breakage, and the analysis suggests that only approximately $50 \%$ of $786-\mathrm{O}^{\text {FOXD1null }}$ cells have intact genomes compared with $80 \%$ of $786-\mathrm{O}$. In response to DNA damage, cells typically phosphorylate $\mathrm{H} 2 \mathrm{AX}(\gamma \mathrm{H} 2 \mathrm{AX})$ at locations of double strand breaks to indicate regions needing DNA repair. We further investigated if $\gamma \mathrm{H} 2 \mathrm{AX}$ levels were also elevated in 786-O $\mathrm{O}^{\text {FOXD1null }}$ cells, and found a similar pattern to TUNEL, although the proportions of nuclei staining with $\gamma \mathrm{H} 2 \mathrm{AX}$ was greater, suggesting that this assay is more sensitive (Fig. 6b). DNA damage is normally repaired during G2/M and cells that have undergone mitosis should display strongly reduced $\gamma \mathrm{H} 2 \mathrm{AX}$ staining. To understand if DNA damage is repaired during G2, we performed an EdU pulse-chase experiment. Although synchronizing cells as shown in Fig. 5a would facilitate this experiment, the synchronization procedure introduces DNA damage, and would confound the analysis. Based on an S phase length of approximately $6 \mathrm{~h}$ (Fig. 5a), we performed an $8 \mathrm{~h}$ pulse to label cells entering G2 (Fig. S6). Expression of pH3 in 786-O showed a peak at $2 \mathrm{~h}$ following EdU wash-out and defined a subpopulation that had synchronously transitioned to mitosis (Fig. 6c). By $4 \mathrm{~h}$ after wash-out, the number of $\mathrm{pH} 3+$ cells had returned to baseline, indicating exit of this subpopulation from mitosis. Immunostaining for $\gamma \mathrm{H} 2 \mathrm{AX}$ in this subpopulation revealed that staining peaked concomitantly with $\mathrm{pH} 3$ and declined to $0 \% 4 \mathrm{~h}$ after wash-out (Fig. 6d), showing a complete reset of the chromosomal markers for DNA damage and suggesting comprehensive DNA damage repair in 786-O. As anticipated, 786- $\mathrm{O}^{\text {FOXD1null }}$ did not show a pH3 peak (Fig. 6c), but $\gamma \mathrm{H} 2 \mathrm{AX}$ immunostaining of the $\mathrm{pH} 3+$ subpopulation did show a peak at $2 \mathrm{~h}$ after wash-out (Fig. 6d). However, $\gamma \mathrm{H} 2 \mathrm{AX}$ declined only modestly following the peak, showing that chromosomal damage markers were not reset, and suggesting remaining DNA damage following mitosis in $786-\mathrm{O}^{\mathrm{FOXD} 1 n u l l}$. These findings were replicated with 3 different EdU-pulse labeling time periods (Fig. S6). To determine if DNA damage was reduced in all 786-O ${ }^{\text {FOXD1null }}$ cells, or if the 786-O culture may be a mosaic of cells in which DNA damage is repaired and cells in which it is not, we compared nuclei of 786-O and 786-O ${ }^{\text {FOXD1null }}$ cells immunostained with $\gamma \mathrm{H} 2 \mathrm{AX}$, phalloidin, and DAPI to define mitotic cells with colocalized chromatin and actin (Fig. 6e). Interestingly, while $\gamma \mathrm{H} 2 \mathrm{AX}$ was not detected in cells going through anaphase in either 786-O or 786-O ${ }^{\text {FOXD1null }}$, we found a significant number of cells with $\gamma \mathrm{H} 2 \mathrm{AX}$ in at least one daughter cell during cytokinesis, indicating that the sustained DNA damage found in 786$\mathrm{O}^{\text {FOXD1null }}$ is likely due to strand breaks that arise during mitosis (Table S4).

Taken together, our data shows that FOXD1 is required for 786-O tumor cells to undergo mitosis with DNA damage repair of both daughter cells. To understand if this mechanism could underlie the reduced patient survival seen in ccRCC cases with high FOXD1 tumor expression (Fig. 1a), we performed a correlation analysis between FOXD1 expression in ccRCC tumors and biological pathways. First, FOXD1 expression was correlated with expression of all other genes in ccRCC transcriptomes from the TCGA database (Fig. 6f). Strongly correlated genes were then analyzed using Gene Set Enrichment Analysis to identify biological pathways (Fig. 6g). FOXD1 expression was associated with cell cycle checkpoint pathways and pathways controlling chromosomal architecture in mitosis, suggesting that FOXD1 may indeed participate in these processes in patient tumors. The top common pathway components include members of the nuclear pore complex (SEC13, NUP37), centromere subunits (CENPM, CENPN, CENP Q), and enzymes (PPP2R5A, PPP2R5B, CDC20, BUB1). Candidate genes within the top scoring pathways include kinases and phosphatases involved in phosphorylation of Histone H3 (Fig. S7).

\section{Discussion}

Our analysis indicates that FOXD1 is required for the appropriate phosphorylation of histone $\mathrm{H} 3$, which maintains DNA integrity during mitosis. The capacity for DNA damage repair differs widely between different types of tumors, and ccRCC displays moderate genomic damage [26]. ccRCC is generally resistant to both cisplatinum and radiation-induced DNA damage, suggesting active DNA damage repair in these tumors. Our data suggests that FOXD1 expression is necessary for proper cell division and may serve a protective role during mitosis in tumor cells predisposed to severe genetic damage.

Based on previous work demonstrating a role for FOXD1 in controlling expression of MICU1, which 
A.
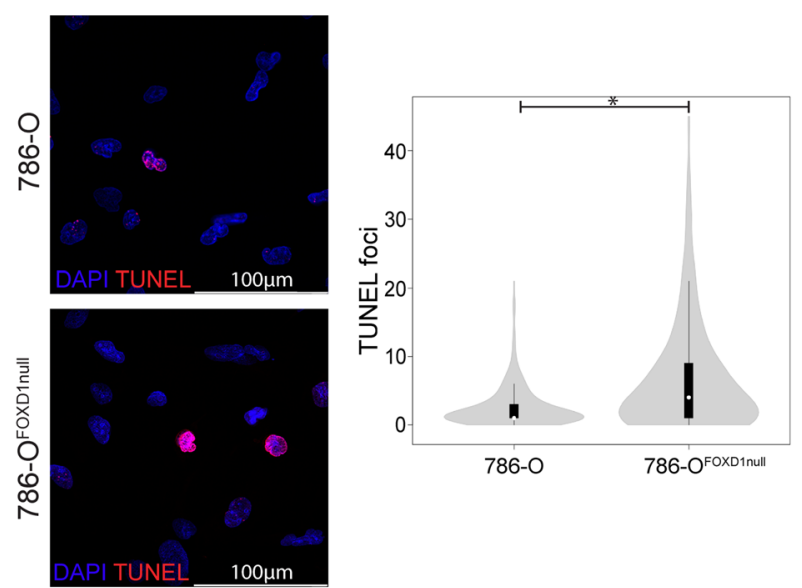

C.
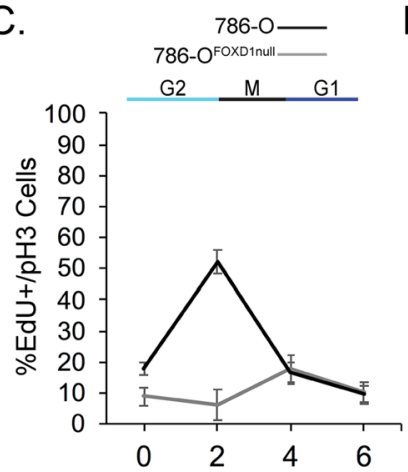

D.

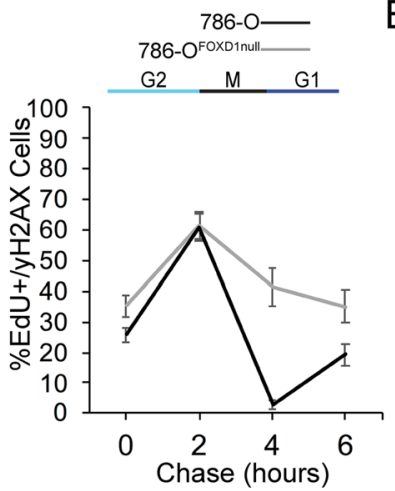

B.
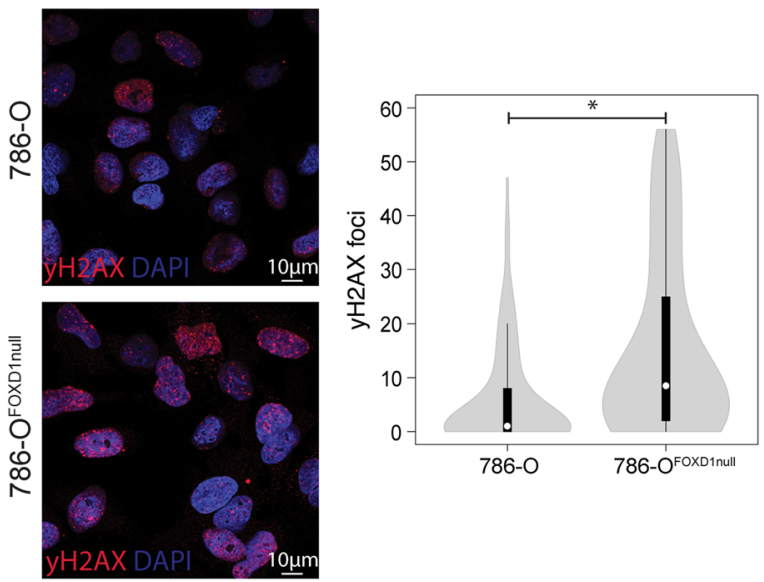

E.
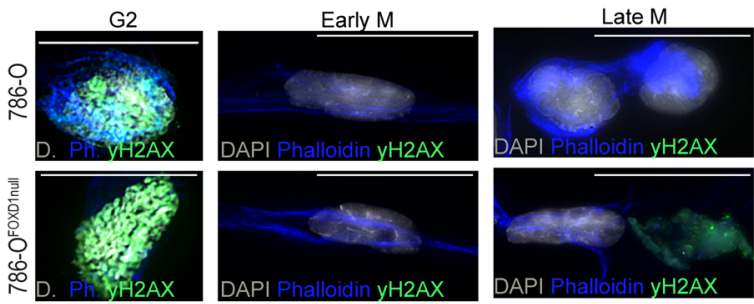

F.

FOXD1 gene correlation

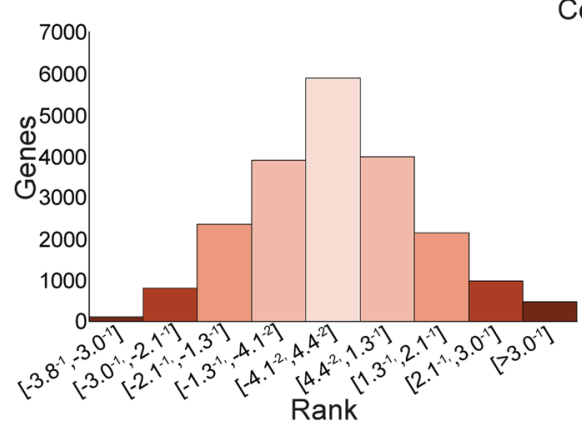

G.

Correlation

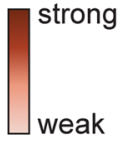

Fig. 6 FOXD1 is necessary for maintaining DNA integrity following mitosis. a Representative TUNEL (red) staining of 786-O versus 786-OFOXD1null, counterstained with DAPI (blue). Nuclear TUNEL foci were counted and compared using Student's t-test $(N=3)$. ${ }^{*} p<0.05$ b Representative YH2AX (red) immunocytochemistry of 786-O versus 786-O ${ }^{\text {FOXD1null }}$ cells, counterstained with DAPI (blue). Nuclear $\gamma \mathrm{H} 2 \mathrm{AX}$ foci were counted and compared using Student's t-test $(N=3)$. ${ }^{*} p<0.05$ c EdU pulse-chase cell cycle progression analysis. Cells in G2 were labeled with EdU following 8 $\mathrm{h}$ incubation with EdU. Labeled cells were analyzed for $\mathrm{pH} 3$ expression every $3 \mathrm{~h}$ post-labeling using immunocytochemistry. One hundred EdU+ cells were analyzed $(\mathrm{N}=3)$. d Analysis of EdU labeled cells in $\mathrm{G} 2$ for $\mathrm{\gamma H} 2 \mathrm{AX}$ expression every $2 \mathrm{~h}$ post- labeling by immunocytochemistry. One hundred EdU+ cells were analyzed ( $N=3$ ). e Immunocytochemistry analysis of $\mathrm{\gamma H} 2 \mathrm{AX}$ (green) at different phases of the cell cycle, costained with DAPI (gray) and phalloidin (blue). Early M represented by cells in metaphase and late M representing cells undergoing cytokinesis and entering post-mitosis G1. f Correlation of mean FOXD1 expression against all genes found in the KIRC TCGA database. Ranked values scored using the Pearson correlation coefficient. $\mathbf{g}$ Gene set enrichment analysis of ranked FOXD1-correlated genes shows enrichment of REACTOME pathways related to mitotic entry and progression 
regulates calcium flux in the mitochondrion, we hypothesized that reduced proliferative capacity of FOXD1 null tumor cells may be due to reduced energy production capacity [14]. Metabolic analyses revealed a bioenergetic shift away from mitochondrial respiration but also demonstrated compensation by increased glycolysis resulting in unaltered ATP production. In light of this finding, reduced energy production does not explain the reduced proliferative capacity. Despite maintained energy production, a shift towards glycolysis may have consequences for basic cell behaviors through the production of a range of metabolites for biosynthetic pathways, and in other tumor cell contexts this is characteristic of increased proliferation [27]. Thus, it is counterintuitive that the bioenergetic shift seen in FOXD1 null cells would explain reduced proliferation, and the cause is more likely to be a direct effect on the cell cycle.

The loss of histone $\mathrm{H} 3$ phosphorylation seen upon FOXD1 inactivation does not prevent entry into mitosis, and compensatory mechanisms, such as CENPA nucleosome formation, may allow mutant cells to complete the cell cycle [28]. We found centromere subunits associated with this complex were highly correlated with FOXD1 expression, further supporting this possibility (Fig. 6g). However, the CENPA nucleosome complex is known to be unstable in vivo and this compensatory mechanism may be limited to cell culture $[29,30]$, providing an explanation for the difficulty in generating tumors from 786- $\mathrm{O}^{\text {FOXD1null }}$ xenografts.

FOXD1 expression is tightly controlled in the adult, and our analyses of healthy human kidney tissue showed no expression in tubule epithelium, which is the cell population of origin for ccRCC [31]. Foxd1 was initially characterized as a regulator of kidney development through studies in knockout mice [4], and it is specifically expressed in the progenitor population of the kidney interstitium [32]. Interestingly, recent gene expression analysis has shown a slightly broader expression pattern for FOXD1 in the human fetal kidney, including a subset of progenitor cells of the tubule epithelium [33]. Thus, the expression of FOXD1 in dedifferentiated tubule epithelial cells in ccRCC may represent partial regression to a developmental progenitor for the tubule epithelium. The nephron progenitor cell population of the developing kidney is highly proliferative, and studies in mouse suggest that it relies heavily on glycolysis, similarly to the ccRCC cell [34]. FOXD1 is located on chromosome 5 approximately 60 megabases from $V H L$, which is the most common primary mutation in ccRCC. Thus, an alternate possibility is that FOXD1 expression becomes deregulated by the genetic hit at the $V H L$ locus that initiates transformation, rather than being activated as a component of a dedifferentiation program.

The finding that FOXD1 expression is mosaic in the majority of tumors indicates that it may be activated or inactivated in subpopulations of tumor cells. Given its role in promoting cell cycle progression and DNA damage repair, FOXD1 would be expected to confer a growth advantage, and for this reason it seems most likely that it is activated in subsets of cells as the tumor ages. Mechanisms governing cellular localization of FOXD1 are not known, and an alternate explanation for the mosaicism that we see in patient tumors may be that nuclear FOXD1 accumulation is dynamic and regulated by environmental factors that differ in distinct regions of tumors. Structure-function studies of the FOXD1 protein and a better understanding of tumor architecture will be required to evaluate these possibilities.

This study uncovers a novel and important role for FOXD1 in controlling division and DNA repair of ccRCC tumor cells. Further studies aimed at defining how the activity of FOXD1 is regulated will determine if this is a tractable therapeutic pathway.

\section{Conclusions}

This work supports a role for FOXD1 as a potent driver of tumor growth in ccRCC. FOXD1 expression inversely correlated with patient outcome and was also shown to be grade and stage dependent. Inactivation of FOXD1 significantly decreased the expression of components of mitochondrial metabolism in ccRCC cells and promoted glycolysis, but did not influence overall energy production. The cell cycle was altered by loss of FOXD1, with a delay in progression through the $G 2 / \mathrm{M}$ checkpoint, which associated with increased DNA damage. Phosphorylation of histone $\mathrm{H} 3$ was lost in FOXD1 null cells, providing an explanation for the increase in mitotic defects. Based on our investigation, we propose that FOXD1 is required for histone $\mathrm{H} 3$ phosphorylation in rapidly cycling ccRCC cells, ensuring that they can proceed through the cell cycle without catastrophic DNA damage. Transcriptomic evidence from human ccRCC tumors correlating FOXD1 expression with expression of kinases and phosphatases that modulate histone $\mathrm{H} 3$ phosphorylation supports this interpretation. Understanding how FOXD1 controls mechanisms governing histone $\mathrm{H} 3$ phosphorylation in ccRCC has potential therapeutic applications that will be explored in future work.

\section{Abbreviations}

TCGA: The Cancer Genome Atlas; ccRCC: Clear cell renal cell carcinoma; ICE: Inference of CRISPR Edits; H3: Histone H3; pH 3: Phosphorylated histone $\mathrm{H} 3$ 


\section{Supplementary Information}

The online version contains supplementary material available at https://doi. org/10.1186/s12885-021-07957-8.

Additional file 1 Table S1: Summary of patient clinical data used for FOXD1 immunohistochemistry analysis. Table S2: Primers used for FOXD1 genotyping and off-target analysis. * Blue indicates primers used for sequencing mismatch region. ${ }^{*}$ Red bases indicate mismatches from FOXD1. Table S3: Primers for reference genes, FOXD1 targets, and mitochondrial metabolism components. Table S4: Nuclear morphology analysis of 786-O and 786-OFOXD1null. *Immunocytochemistry analysis of cells in different phases of the cell cycle after low density plating, based on nuclear and actin morphologies and localization. Percentage values are based on analysis of 100 cells per group across several fields. ${ }^{*}$ Defects panel indicates collection of possible mitotic defects including lack of chromosome condensation (prophase), loss of spindle polarity (metaphase/anaphase), incomplete sister chromosome separation (cytokinesis), and death of daughter cell (post-mitosis G1). Figure S1: FOXD1 grade and stage analyses. (A) FOXD1 expression level comparisons at different ccRCC tumor grades based on transcriptome data from The Cancer Genome Atlas (B) FOXD1 expression level comparisons at different ccRCC tumor stages based on transcriptome data from The Cancer Genome Atlas. (C-D) Kaplan-Meier survival analyses for ccRCC patients with high versus low tumor expression of FOXD1, analyzed based of tumor stage. ${ }^{*} p<0.05$. Figure S2: FOXD1 antibody validation. (A-B) TSA amplification staining for FOXD1 (green) on E12.5 mouse kidneys on normal and FOXD1-null backgrounds. Nuclei counterstained with DAPI (blue), (C-D) Immunohistochemistry staining of adult human kidney tissue $(C)$ and FOXD1-null E12.5 mouse kidney (D). Figure S3: FOXD1 qPCR reference gene selection. (A) Stability scores generated by comparing candidate reference gene assays (Table S3) on equivalent mRNA quantities of 786-O versus 786-OFOXD1null analyzed using the BioRad Reference Gene Selector Tool. Colors of bars denote genes that are over (green) or under the acceptable stability threshold between samples. (B-D) Standard curves for reference genes selected for this study. Figure S4: FOXD1-null cells difficulty in tumor establishment. (A) Xenograft of 786-O and 786- $\mathrm{O}$ FOXDinull into flanks of 6-week old NCG mice. Red dotted line outlines tumors. Resected tumors from shown mice are shown in right-hand corner of image $(B)$ Xenograft growth rate analysis. Figure S5: Histone $\mathrm{H} 3$ phosphorylation analysis. (A-B) Full membranes used for Western Blot analysis, with proteins visualized using the Bio-Rad Stain-Free gel system. Protein loading was quantified in each lane for normalization. (C-F) Full protein blots for histone $\mathrm{H} 3$ and phosphorylated histone $\mathrm{H} 3$ (Ser10) of synchro-

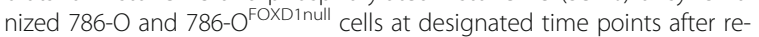
lease from thymidine block. Blue boxes indicate areas used for quantification. (G) Densitometry analysis (Ser10), normalized to total protein in well. Figure S6: CDC2 Phosphorylation analysis. Full membranes and quantification used for western blot analysis of CDC2 (A-B) and phosphorylated forms at T161 (C-D) and Y15 (E-F). All protein levels were normalized to total protein loaded. Figure S7: CyclinB1 and MICU1 protein analysis. Full membranes and quantification used for western blot analysis of CyclinB1 (A-B) and MICU1 (C-D). All protein levels were normalized to total protein loaded. Figure S8: EdU pulse-chase analysis. (A) Labeling schematic of pulse-chase experiment. Cells in S phase incorporate EdU and are labeled (yellow circles). After $8 \mathrm{~h}$ EdU treatment, cells in G2 are labeled with EdU. After $2 \mathrm{~h}$ ( $2 \mathrm{~h}$ chase), labeled cells in $\mathrm{G} 2$ progress into mitosis (M). After an additional $2 \mathrm{~h}$ ( $4 \mathrm{~h}$ chase), labeled cells in $\mathrm{M}$ divide and enter G1. (B) Representative images showing staining of $\mathrm{pH} 3$ and $\mathrm{yH} 2 \mathrm{AX}$ at $2 \mathrm{~h}$ intervals following EdU pulse of both 786-O and 786-OFOXDinull. (C) EdU pulse-chase cell cycle progression analysis. Cells in G2 were labeled with EdU following $6 \mathrm{~h}$ or $10 \mathrm{~h}$ incubation with EdU. Labeled cells were analyzed for $\mathrm{pH} 3$ expression every $2 \mathrm{~h}$ post-labeling using immunocytochemistry. One hundred EdU+ cells were analyzed $(N=3)$. (D) Analysis of EdU labeled cells, for $6 \mathrm{~h}$ or $10 \mathrm{~h}$ inncubations, for $\mathrm{yH} 2 \mathrm{AX}$ expression every $2 \mathrm{~h}$ post- labeling by immunocytochemistry. One hundred EdU+ cells were analyzed $(N=3)$. Figure S9: FOXD1 correlated genes involved in cell cycle regulation. Leading edge analysis of FOXD1 correlated genes from TCGA and top scoring candidates. *indicates kinases linked to phosphorylation of histone $\mathrm{H} 3$.

\section{Acknowledgments}

Seahorse assays were performed and analyzed on a Seahorse XF96 extracellular flux analyzer at Maine Medical Center Physiology Core facility (supported by NIH/NIGMS 3P20GM121301-03). Flow cytometry / cell sorting was performed at the Flow Cytometry Core Facility, LFKRI, New York Blood Center, New York, NY. We extend our sincere thanks to the staff of the New York Blood Center mouse facility for their dedication to maintaining the highest standards of animal care through the COVID-19 pandemic shutdown.

\section{Authors' contributions}

KHB performed all molecular and cellular biology experiments, and was aware of all group allocations throughout animal studies. JLF performed immunohistochemistry analysis of FOXD1 in patient samples. CWL performed all database analyses. IFE collected patient samples and provided insight necessary to compete this project. LO conceptualized and coordinated the project. All authors read and approved the final manuscript.

\section{Funding}

This work was supported by The Assistant Secretary of Defense for Health Affairs endorsed by the Department of Defense, through the Kidney Cancer Research Program under Award No. KC170016 (LO). Opinions, interpretations, conclusions and recommendations are those of the authors and are not necessarily endorsed by the Department of Defense. Funding was also provided by the Maine Cancer Foundation (LO). The funding bodies played no role in the design of the study and collection, analysis, and interpretation of data and in writing the manuscript.

\section{Availability of data and materials}

The datasets analyzed during the current study are available in the TCGA repository, https://portal.gdc.cancer.gov/projects/TCGA-KIRC. All data analyzed during this study are included in this published article. All datasets used and analyzed during the current study are available from the corresponding author on reasonable request.

\section{Declarations}

Ethics approval and consent to participate

Samples from resected tumors were obtained from the Maine Medical Center BioBank, which obtains surgical samples with the written informed consent of patients. The study was approved by the Maine Medical Center Institutional Review Board (IRB \#4202X and IRB \#4392). All animal studies were done in accordance with the National Research Council Guide for the Care and Use of Laboratory Animals, and all experiments were approved by the Institutional Animal Care and Use Committee of the New York Blood Center, where the Rogosin Institute research laboratory is located.

\section{Consent for publication}

Not applicable.

\section{Competing interests}

The authors declare that they have no competing interests.

\section{Author details}

${ }^{1}$ The Rogosin Institute, 310 East 67th Street, New York, NY 10065, USA. ${ }^{2}$ Graduate School of Biomedical Sciences and Engineering, University of Maine, 168 College Ave, Orono 04469, ME, USA. ${ }^{3}$ Maine Medical Center Research Institute, 81 Research Drive, Scarborough, ME 04074, USA. ${ }^{4}$ Current affiliation: ICON PIc, 2100 Pembrook Parkway, North Wales 19446, PA, USA.

\section{Received: 9 September 2020 Accepted: 23 February 2021}

Published online: 24 March 2021

\section{References}

1. Lam EW, Brosens JJ, Gomes AR, Koo CY. Forkhead box proteins: tuning forks for transcriptional harmony. Nat Rev Cancer. 2013;13(7):482-95.

2. Bruno S, Bussolati B, Grange C, Collino F, Graziano ME, Ferrando U, et al. CD133+ renal progenitor cells contribute to tumor angiogenesis. Am J Pathol. 2006;169(6):2223-35.

3. Qian CN, Huang D, Wondergem B, Teh BT. Complexity of tumor vasculature in clear cell renal cell carcinoma. Cancer. 2009;115(10 Suppl):2282-9. 
4. Hatini V, Huh SO, Herzlinger D, Soares VC, Lai E. Essential role of stromal mesenchyme in kidney morphogenesis revealed by targeted disruption of winged Helix transcription factor BF-2. Genes Dev. 1996;10(12):1467-78.

5. Zhao YF, Zhao JY, Yue H, Hu KS, Shen H, Guo ZG, et al. FOXD1 promotes breast cancer proliferation and chemotherapeutic drug resistance by targeting p27. Biochem Biophys Res Commun. 2015:456(1):232-7.

6. Nakayama S, Soejima K, Yasuda H, Yoda S, Satomi R, Ikemura S, et al. FOXD1 expression is associated with poor prognosis in non-small cell lung cancer. Anticancer Res. 2015;35(1):261-8.

7. Gao YF, Zhu T, Mao XY, Mao CX, Li L, Yin JY, et al. Silencing of Forkhead box D1 inhibits proliferation and migration in glioma cells. Oncol Rep. 2017; 37(2):1196-202.

8. Ju W, Yoo BC, Kim IJ, Kim JW, Kim SC, Lee HP. Identification of genes with differential expression in chemoresistant epithelial ovarian cancer using high-density oligonucleotide microarrays. Oncol Res. 2009;18(2-3):47-56.

9. Fetting $\lrcorner$, Guay JA, Karolak MJ, lozzo RV, Adams DC, Maridas DE, et al. FOXD1 promotes nephron progenitor differentiation by repressing decorin in the embryonic kidney. Development (Cambridge, England). 2014;141;(1): 17-27.

10. Jassal B, Matthews L, Viteri G, Gong C, Lorente P, Fabregat A, et al. The reactome pathway knowledgebase. Nucleic Acids Res. 2020;48(D1):D498d503

11. Shannon P, Markiel A, Ozier O, Baliga NS, Wang JT, Ramage D, et al. Cytoscape: a software environment for integrated models of biomolecular interaction networks. Genome Res. 2003;13(11):2498-504

12. Williams RD, Elliott AY, Stein N, Fraley EE. In vitro cultivation of human renal cell cancer. II. Characterization of cell lines. In Vitro. 1978;14(9):779-86

13. Quintero-Ronderos P, Laissue P. The multisystemic functions of FOXD1 in development and disease. J Mol Med (Berlin, Germany). 2018;96(8):725-39

14. Shanmughapriya S, Tomar D, Dong Z, Slovik KJ, Nemani N, Natarajaseenivasan K, et al. FOXD1-dependent MICU1 expression regulates mitochondrial activity and cell differentiation. Nat Commun. 2018;9(1):3449

15. Pan F, Li M, Chen W. FOXD1 predicts prognosis of colorectal cancer patients and promotes colorectal cancer progression via the ERK 1/2 pathway. Am J Transl Res. 2018;10(5):1522-30

16. Briston T, Stephen JM, Thomas LW, Esposito C, Chung YL, Syafruddin SE, et al. VHL-mediated regulation of CHCHD4 and mitochondrial function. Front Oncol. 2018:8:388.

17. Kim JW, Tchernyshyov I, Semenza GL, Dang CV. HIF-1-mediated expression of pyruvate dehydrogenase kinase: a metabolic switch required for cellular adaptation to hypoxia. Cell Metab. 2006;3(3):177-85.

18. Wang X, Zhang L, O'Neill A, Bahamon B, Alsop DC, Mier JW, et al. Cox-2 inhibition enhances the activity of sunitinib in human renal cell carcinoma xenografts. Br J Cancer. 2013;108(2):319-26.

19. Bhatt RS, Wang X, Zhang L, Collins MP, Signoretti S, Alsop DC, et al. Renal cancer resistance to antiangiogenic therapy is delayed by restoration of angiostatic signaling. Mol Cancer Ther. 2010;9(10):2793-802.

20. Wang Y, Qiu C, Lu N, Liu Z, Jin C, Sun C, et al. FOXD1 is targeted by miR$30 a-5 p$ and miR-200a-5p and suppresses the proliferation of human ovarian carcinoma cells by promoting p21 expression in a p53-independent manner. Int J Oncol. 2018;52(6):2130-42

21. Lindqvist A, Rodríguez-Bravo V, Medema RH. The decision to enter mitosis: feedback and redundancy in the mitotic entry network. J Cell Biol. 2009; 185(2):193-202.

22. Strelkov IS, Davie JR. Ser-10 phosphorylation of histone H3 and immediate early gene expression in oncogene-transformed mouse fibroblasts. Cancer Res. 2002;62(1):75-8.

23. Oktay K, Buyuk E, Oktem O, Oktay M, Giancotti FG. The c-Jun N-terminal kinase JNK functions upstream of Aurora B to promote entry into mitosis. Cell Cycle. 2008;7(4):533-41.

24. Hendzel MJ, Wei Y, Mancini MA, Van Hooser A, Ranalli T, Brinkley BR, et al. Mitosis-specific phosphorylation of histone $\mathrm{H} 3$ initiates primarily within pericentromeric heterochromatin during G2 and spreads in an ordered fashion coincident with mitotic chromosome condensation. Chromosoma. 1997;106(6):348-60.

25. Wei $Y, Y u$ L, Bowen J, Gorovsky MA, Allis CD. Phosphorylation of histone H3 is required for proper chromosome condensation and segregation. Cell. 1999:97(1):99-109.

26. Cancer_Genome_Atlas_Research_Network. Comprehensive molecular characterization of clear cell renal cell carcinoma. Nature. 2013; 499(7456):43-49.
27. Lunt SY, Vander Heiden MG. Aerobic glycolysis: meeting the metabolic requirements of cell proliferation. Annu Rev Cell Dev Biol. 2011:27:441-64.

28. Yoda K, Ando S, Morishita S, Houmura K, Hashimoto K, Takeyasu K, et al. Human centromere protein a (CENP-A) can replace histone $\mathrm{H} 3$ in nucleosome reconstitution in vitro. Proc Natl Acad Sci U S A. 2000;97(13): 7266-71.

29. Dimitriadis EK, Weber C, Gill RK, Diekmann S, Dalal Y. Tetrameric organization of vertebrate centromeric nucleosomes. Proc Natl Acad Sci U S A. 2010;107(47):20317-22.

30. Bui M, Dimitriadis EK, Hoischen C, An E, Quénet D, Giebe S, et al. Cell-cycledependent structural transitions in the human CENP-A nucleosome in vivo. Cell. 2012;150(2):317-26

31. Frew IJ, Moch $\mathrm{H}$. A clearer view of the molecular complexity of clear cell renal cell carcinoma. Annu Rev Pathol. 2015;10:263-89.

32. Kobayashi A, Mugford JW, Krautzberger AM, Naiman N, Liao J, McMahon AP. Identification of a multipotent self-renewing stromal progenitor population during mammalian kidney organogenesis. Stem Cell Rep. 2014;3(4):650-62.

33. Lindstrom NO, Guo J, Kim AD, Tran T, Guo Q, De Sena Brandine G, et al. Conserved and divergent features of Mesenchymal progenitor cell types within the cortical Nephrogenic niche of the human and mouse kidney. Journal of the American Society of Nephrology : JASN. 2018.

34. Liu J, Edgington-Giordano F, Dugas C, Abrams A, Katakam P, Satou R, et al. Regulation of nephron progenitor cell self-renewal by intermediary metabolism. J Am Soc Nephrol. 2017;28(11):3323-35.

\section{Publisher's Note}

Springer Nature remains neutral with regard to jurisdictional claims in published maps and institutional affiliations.

\section{Ready to submit your research? Choose BMC and benefit from:}

- fast, convenient online submission

- thorough peer review by experienced researchers in your field

- rapid publication on acceptance

- support for research data, including large and complex data types

- gold Open Access which fosters wider collaboration and increased citations

- maximum visibility for your research: over $100 \mathrm{M}$ website views per year

At BMC, research is always in progress.

Learn more biomedcentral.com/submissions 